\title{
Comparing Mechanistic Reasoning in Open and Guided Inquiry Physics Activities
}

\author{
Rosemary Wulf, Kathleen Hinko* ${ }^{*}$ and Noah Finkelstein ${ }^{*}$ \\ ${ }^{*}$ Department of Physics and ${ }^{\dagger}$ JILA NSF Physics Frontier Center for Atomic, Molecular and Optical Physics, \\ University of Colorado Boulder, CO 80309, USA
}

\begin{abstract}
Inquiry activities can provide students with the chance to experiment and to externalize their reasoning. To examine the impacts of level of guidance in inquiry-based activities on students' mechanistic reasoning, we analyze middle school students' scientific notebooks from an afterschool program by applying a coding scheme that is modified from Russ (Russ, R. et al.. (2008). Sci. Ed., 92: 499-525.). We compare students' mechanistic reasoning in two inquiry physics curricula, one that is guided and another that is more open-ended inquiry. We find that students exhibit more types and more overall mechanistic reasoning in the open curriculum. We also code the curricula and find that students have more opportunities to practice mechanistic reasoning in the open-ended curriculum. We examine why students take the opportunities provided to them in both curricula and the implications for both informal and formal curriculum design.
\end{abstract}

Keywords: Physics education research, informal science education, curriculum

PACS: 01.40.Fk, 01.40.-d

\section{INTRODUCTION}

Scientific inquiry involves studying the natural world and proposing explanations to phenomena that are based on gathered evidence. The use of scientific inquiry in science classrooms is called for by the National Science Education Standards (NSES) [1]. In the classroom context, the degree to which an inquirybased lesson in science is structured by a teacher or facilitator falls on a continuum from less guided (or more open-ended) to more heavily guided inquiry. More "open" inquiry is characterized by the learner taking responsibility for asking questions, designing experiments and communicating scientifically [2]. One function of inquiry is described by the National Research Council Report on Inquiry in the NSES: "Guided inquiry can best focus learning on the development of particular science concepts. More open inquiry will afford the best opportunities for cognitive development and scientific reasoning" [2]. In this work, we examine the connection between the "openness" of inquiry activities and student reasoning.

One key type of reasoning seen in scientific inquiry is mechanistic reasoning. Reasoning that is mechanistic describes the underlying mechanism, and each of its sequential stages, that gives rise to phenomena [3]. Central to this style of reasoning are entities and activities. Entities are the constituent pieces that engage in activities to produce phenomena.

Mechanistic reasoning can play an important role in science education. In many science classrooms emphasis is placed on learning what is "correct" based on what is written in a textbook. This focus directly contrasts with how scientists analyze proposed explanations, which is based on evidence, models, and arguments in support of ideas, not simply on authority. Mechanistic reasoning can be used to formulate an argument or model about the causes underlying physical phenomena [3]. This process is aligned with one of the essential features of inquiry lessons: learners formulate explanations from evidence [2]. In this work, we modify and apply an established mechanistic reasoning rubric to analyze middle school students' written documentation of physics activities in an afterschool program. We compare mechanistic reasoning exhibited by the same set of students engaged with two different curricular approaches, one that lands on the guided end of the spectrum and the other that is more open. Additionally, we apply the mechanistic reasoning scheme to analyze the curriculum to determine what reasoning opportunities were afforded to students.

\section{INQUIRY CURRICULA}

This study was conducted in an informal afterschool program called Partnerships for Informal Science Education in the Community (PISEC) sponsored by the University of Colorado Boulder and the JILA Physics Frontier Center [4]. PISEC partners with schools and community organizations to bring university physics students together with K-8 children for weekly activity sessions during the semester.

The original PISEC curriculum (Fall 2011) was developed with the primary goals of promoting mastery of physics concepts and developing an 
understanding of the nature of science - goals which are aligned with those of traditional classroom settings [5]. Portions of a research-based inquiry-oriented curriculum [6] were adapted to facilitate these goals and pre/post tests were built into the activities to assess students' conceptual understanding. For Fall 2011, the content area was simple, series electrical circuits. Students predicted which configurations of wire and batteries would light a bulb, tested the configurations, and wrote rules to explain why each configuration would or would not light. The activities were highly structured with a strict division between predicting, testing and rule-making for each activity. Furthermore, the entire curriculum had a worksheet-like format, including multiple choice pre/post tests and shortanswers that needed to fit into boxes. These activities offered little opportunity for students to decide which questions to answer, to pose questions, or to design their own investigations. A few activities incorporated more student-structured investigations (see Discussion); however, these questions were located toward the end of the curriculum and most students did not have enough time to complete more than one of these activities. Based on observations and pre/post test analysis, by the end of the semester students were able to correctly build, identify and explain circuit configurations that would cause single bulbs to light,

an outcome shown in prior semesters [7].

While content learning was evident, the students, teachers and volunteers reported that the program was not very engaging and expressed a desire to do more hands-on experiments. Thus, for Spring 2012, a new curriculum was developed that was designed to be more hands-on and less directed in order to support the informal learning goals of increasing enthusiasm for science and promoting science identity, while continuing to increase content knowledge [5]. The Spring 2012 transformed curriculum focused on light and optics and used a combination of common science toys, PhET computer simulations [8] and college laboratory equipment. The formats of the prompts for each activity were changed from limited-response to free response, encouraging more student responsibility in answering as well as greater amounts of written and pictorial communication. For example, one activity involved examining a fiber optic lamp. The prompt asked "How does light get from inside the base to the ends of the fibers?" The prompt also asked students to draw a picture of how the light gets to the end of the fibers. This type of prompt does not direct students to a "correct answer" but encouraged students to come up with their own reasoning. Students were also encouraged to separately document any activities they designed themselves in the course of exploring the prescribed activities. This opportunity for self- designed activity is the most aligned with open inquiry and was designed to promote student agency.

In prior analysis of these curricular changes, we found that students exhibit significant increases in both agency (student-directed choice of activity) and communication skills (written words and drawings) in the more open (Spring 2012) curriculum [9]. These changes demonstrate a shift of responsibility in the curriculum from the facilitator to the learner [2], and thus indicate decreased written guidance in the newer curriculum as compared to the original.

\section{STUDY METHODS}

In the PISEC program, students participate in the practice of documenting their work in a scientific

TABLE 1. Interpretation of the categories for mechanistic reasoning outlined in [11] as applied to science notebooks.

\begin{tabular}{|c|c|}
\hline Category & Description \\
\hline \begin{tabular}{|l|} 
1. Describing \\
Target \\
Phenomena \\
\end{tabular} & $\begin{array}{l}\text { Students state, make a prediction about, } \\
\text { or draw the outcome of their experiment } \\
\text { or phenomena that they observed. }\end{array}$ \\
\hline $\begin{array}{l}\text { 2. Identifying } \\
\text { Setup } \\
\text { Conditions }\end{array}$ & $\begin{array}{l}\text { Students state what they did before they } \\
\text { started the experiment to make the } \\
\text { outcome happen, mention their setup, or } \\
\text { mention changing their setup. }\end{array}$ \\
\hline $\begin{array}{l}\text { 3. Identifying } \\
\text { Entities }\end{array}$ & $\begin{array}{l}\text { Students specifically list or draw entities } \\
\text { they are working with in their experiment } \\
\text { without detailing their interactions. }\end{array}$ \\
\hline $\begin{array}{l}\text { 4. Identifying } \\
\text { Activities }\end{array}$ & $\begin{array}{l}\text { Students explain how the entities interact } \\
\text { to produce the phenomena or result of } \\
\text { their experiment or draw a picture of an } \\
\text { entity doing an action. Generally involves } \\
\text { the use of a verb to describe an action the } \\
\text { entities were engaged in. }\end{array}$ \\
\hline $\begin{array}{l}\text { 5. Identifying } \\
\text { Properties } \\
\text { of Entities }\end{array}$ & $\begin{array}{l}\text { Students state, or explain with pictures, } \\
\text { what properties an entity has that make } \\
\text { the phenomena or outcome of their } \\
\text { experiment happen. We use this code } \\
\text { whenever properties of either entities or } \\
\text { phenomena in the system are described. }\end{array}$ \\
\hline $\begin{array}{l}\text { 6. Identifying } \\
\text { Organization } \\
\text { of Entities }\end{array}$ & $\begin{array}{l}\text { Students state, or draw a picture } \\
\text { detailing, how entities must be spatially } \\
\text { organized in relation to each other to } \\
\text { make the phenomena happen. }\end{array}$ \\
\hline 7. Chaining & $\begin{array}{l}\text { Students use what they learned in an } \\
\text { activity or series of activities to make a } \\
\text { prediction or formulate a rule that should } \\
\text { hold in the future, predict what changes } \\
\text { must have occurred in the entities to give } \\
\text { rise to a new phenomenon, predict what } \\
\text { entities must be interacting to make a } \\
\text { certain phenomena happen, or } \\
\text { hypothesize about what activities entities } \\
\text { could do to make a new phenomenon. }\end{array}$ \\
\hline nalogy & $\begin{array}{l}\text { Students compare the target phenomenon } \\
\text { to another phenomenon. }\end{array}$ \\
\hline
\end{tabular}


notebook. To study mechanistic reasoning, we examined the students' notebooks, which have been shown to be a reliable assessment tool for other types of student performance [10]. We closely follow the coding scheme developed by Russ, Scherr and colleagues, which they used to analyze mechanistic reasoning in student scientific classroom discussions [11]. To apply this coding rubric to written documentation in the context of PISEC, we adapted eight of their nine categories of mechanistic reasoning. The ninth category is relevant to body language and gestures, which we did not capture. Table 1 summarizes our interpretations of and modifications to the mechanistic reasoning coding scheme.

We analyzed the notebooks of 12 students from two middle schools who participated in the program both Fall 2011 (guided) and Spring 2012 (open) semesters. For each activity the students worked on, we identified what categories of mechanistic reasoning they used to describe what they were doing. For each activity we only identified the presence of a category; we did not count the number of times each category of mechanistic reasoning was used in each activity. We chose this counting scheme because most activities were chunked to explore only one particular phenomenon, and thus we were unable to tell the difference between multiple counts of the same type of reasoning within an activity. Two researchers agreed on the codes in four notebooks. One of the two researchers coded the remaining twenty notebooks. Additionally, we analyzed the opportunities for mechanistic reasoning presented in both curricula by assessing the possible ways to which students could respond to the given activity prompts.

\section{MECHANISTIC REASONING EXHIBITED BY STUDENTS}

In order to compare mechanistic reasoning between the more guided (Fall 2011) and more open (Spring 2012) inquiry curricula, we look across the total amounts of the 8 types of written reasoning aggregated for all 12 students over the course of one semester (Figure 1). While there were more instances of describing target phenomena and identifying organization of entities in the more guided curriculum, there were more counts of identifying setup conditions, identifying activities, identifying properties of entities, and chaining in the more open curriculum. Thus, the more open inquiry activities elicited more varied types of reasoning. Furthermore, the open inquiry had a higher number of total counts of reasoning with $343 \pm$ 13 counts of reasoning while the guided inquiry had a total of $303 \pm 13$ counts of reasoning (error is standard error of the proportion). On average, students in the open inquiry curriculum exhibited $28.6 \pm 7.2$ total counts of reasoning per student and students in the guided curriculum exhibited $25.4+4.8$ total counts of reasoning per student (error is standard error), so there is no statistical difference between the student averages.

\section{Mechanistic Reasoning Exhibited by Students in} Inquiry Activities

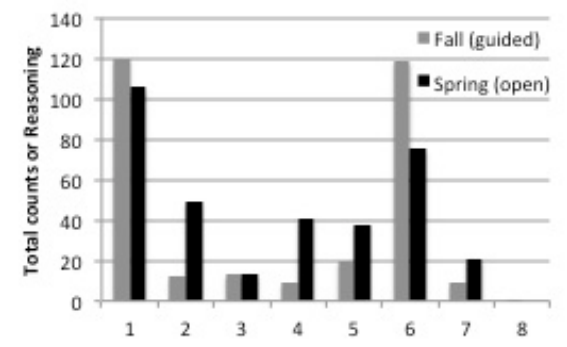

FIGURE 1. Comparison of written reasoning exhibited by students for guided curriculum and more open curriculum. A contingency table analysis shows a significant difference between populations, $\mathrm{p}<.001$.

\section{OPPORTUNITIES PROVIDED FOR MECHANISTIC REASONING}

In order to analyze the opportunities presented to students for mechanistic reasoning, we analyzed the prompts that were asked in each activity that the 12 students completed. For each prompt, we determined which types of reasoning could to used to formulate an answer to each question based on the language of the prompts. For example, a prompt in the Spring 2012 curriculum is "How does the light get from inside the base to the ends of the fibers [in a fiber optic lamp]?" Students could reasonably answer by identifying setup conditions (a light must be shined at the base of the fibers), identifying activities (the light bounces off of the inside of the fibers), identifying properties of entities (the inside of the fibers act reflectively), and identifying organization of entities (the light starts at the base and reflects back and forth until it reaches the end). While this analysis does not mean that the students cannot use other types of reasoning, it does not make much sense to answer this question by simply stating the target phenomena (the ends of the fibers glow), or simply listing the entities involved. We did not code for chaining or analogy opportunities in this case, as the question did not specifically ask for students to compile information that they learned in any specific activity nor did it specifically ask for students to make an analogy.

Figure 2 shows the aggregated counts of the opportunities available for students in the activities that they completed. The total counts of reasoning in the guided and open curriculum are $404 \pm 16$ and 733 \pm 16 , respectively. From this analysis, we see that 
students had more total opportunities for reasoning and more opportunities for varied types of reasoning in the open as compared to the guided curriculum.

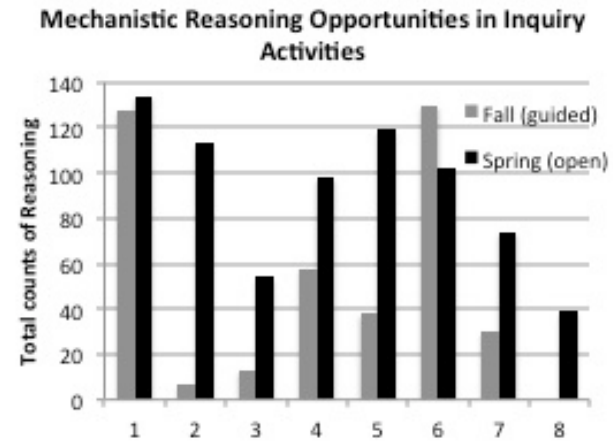

FIGURE 2. Comparison of reasoning opportunities in guided curriculum and more open curriculum. Contingency table analysis shows a significant difference between curricula, $\mathrm{p}<.001$.

To examine how students took advantage of opportunities presented to them, we look at three individual activities. The Rules of Light Bulbs activity was chosen from the guided curriculum because it required short answers rather than simple yes or no statements. The Light the Flashlight activity was the most open inquiry activity in the guided curriculum, and the Hologram Chamber was the most popular activity in the open curriculum. Figure 3 shows data from these activities. The Rules of Light Bulbs activity provided opportunities for 3 types of reasoning, which was one of the activities with the most opportunities from this curriculum. Students, however, exhibited only 2 types of reasoning in their written work. In contrast, the Hologram Chamber activity provided opportunities for 5 types of reasoning, and students

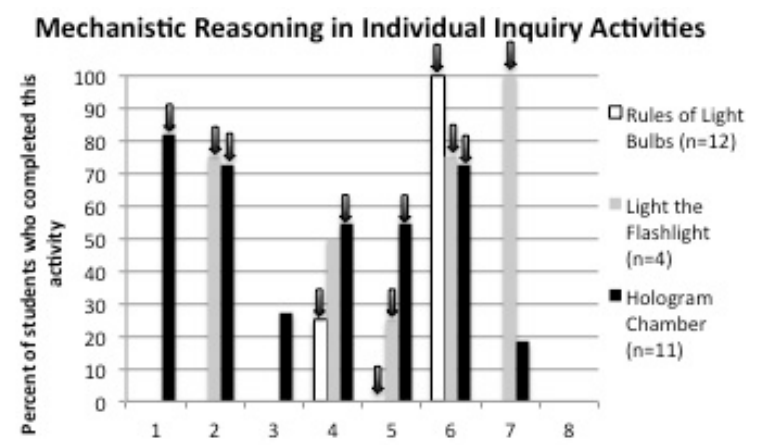

FIGURE 3. Mechanistic reasoning exhibited for three individual activities. Opportunities for reasoning are indicated with an arrow.

exhibited all of these plus an additional 2 reasoning types. Light the Flashlight was the most open activity that was provided; unfortunately, due to its location at the end of the curriculum, only 4 students were able to complete it. The varied types of mechanistic reasoning exhibited in this prompt indicate that an open prompt from the topic of circuits can initiate varied mechanistic reasoning comparable to open prompts from the topic of optics.

\section{DISCUSSION}

We have demonstrated the application of a modified mechanistic reasoning framework to analyze both curricular opportunities for students and student written responses to these prompts. In the more open inquiry activities, we find students are provided with more and varied opportunities for mechanistic reasoning compared to guided activities. We have also shown that students actually exhibit more and varied written reasoning in their science notebooks for open inquiry activities. Students take up the opportunities provided to them in both curricula but also expand on their reasoning with the open inquiry. The more reasoning codes found in a student's work the more compelling the evidence is that the student is reasoning mechanistically [11]. Thus we have more evidence of reasoning in the open inquiry curriculum.

We recognize the written data analyzed here does not include verbal reasoning performed by the students during PISEC. Students' often document their investigations in their notebooks after performing mechanistic reasoning as part of small group discussion. Future work would seek to capture mechanistic reasoning as part of student dialogue while inquiry activities are being explored in real time.

\section{ACKNOWLEDGMENTS}

We thank the JILA NSF Physics Frontier Center and the PER group at $\mathrm{CU}$ Boulder. This work is funded by NSF Grant \#1125844.

\section{REFERENCES}

1. National Research Council, National Science Education Standards (p. 23). Washington, DC: NAP (1996).

2. National Research Council Inquiry and the NSES (p. 30). Washington, DC: NAP (2000).

3. R. Russ, et al., Sci. Ed., 93: 875-891 (2009).

4. PISEC: http://www.colorado.edu/physics/PISEC

5. National Research Council, Learning Science in Informal Environments. NAP, 2009.

6. S. Robinson, F. Goldberg, and V. Otero, "Physics and Everyday Thinking," Its About Time, INC.

7. J. Bartley, L. Mayhew and N. Finkelstein, PERC Proceedings, AIP Press, pp. 93-96 (2009).

8. PhET: http://phet.colorado.edu/

9. R. Wulf, K. Hinko and N. Finkelstein, PERC Proceedings, AIP Press, 2012.

10. M. Ruiz-Primo, Int. J. Sci. Educ, 26, 1477-1506 (2004).

11. Russ, R. S., Scherr, R. E., Hammer, D. and Mikeska, J. (2008), Sci. Ed., 92: 499-525. 